\title{
Air reduction of intussusception after abdominal blunt trauma and a literature review
}

\author{
So Ra Kwon, Sang Ook Ha, Young Taeck Oh, You Dong Sohn \\ Department of Emergency Medicine, Hallym University Medical Center, Hallym University Sacred Heart \\ Hospital, Anyang, Korea
}

The typical presentation of intussusception includes intermittent severe abdominal pain, vomiting, rectal bleeding, and the presence of an abdominal mass. We present a case of intussusception after abdominal blunt trauma along with a literature review. A 4-year-old girl was admitted to the emergency department after a bicycle accident. She complained of progressively worsening abdominal pain, but there was no vomiting, fever, bloody stool, or abdominal mass. She was finally diagnosed with traumatic intussusception by ultrasonography and treated with air reduction. Because the typical symptoms are unusual in traumatic intussusception, close attention must be paid to avoid a delayed diagnosis.

Keywords Intussusception; Pediatrics; Wounds and injuries
elSSN: 2383-4625

Received: 6 October 2015

Revised: 26 October 2015

Accepted: 1 November 2015

Correspondence to: You Dong Sohn Department of Emergency Medicine, Hallym University Medical Center, 22 Gwanpyeong-ro 170beon-gil, Dongan-gu, Anyang 14068, Korea E-mail: medysohn@hallym.or.kr

Wapsule
Wummary is already known
$\begin{aligned} & \text { The typical presentation of intussusception is intermittent severe abdominal } \\ & \text { pain, vomiting, rectal bleeding, and the presence of an abdominal mass. }\end{aligned}$
What is new in the current study
The symptoms of traumatic intussusception may not be typical and greater at-
tention is needed to avoid delayed diagnosis.

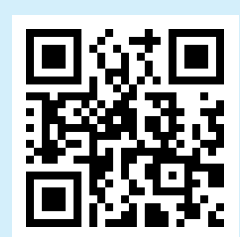

How to cite this article:

Kwon SR, Ha SO, Oh YT, Sohn YD. Air reduction of intussusception after abdominal blunt trauma and a literature review. Clin Exp Emerg Med 2016;3(1):59-62.

This is an Open Access article distributed under the terms of the Creative Commons Attribution Non-Commercial License (http:// creativecommons.org/licenses/by-nc/3.0/). 


\section{INTRODUCTION}

Intussusception is a common cause of intestinal obstruction in children between the ages of 6 and 36 months. Although idiopathic intussusception is most common in children, recent studies show adenovirus as a possible risk factor. ${ }^{1}$ Further, conditions such as Meckel's diverticulum, polyps, or small bowel lymphoma are other known etiologies. However, traumatic intussusception is quite rare. A recent review of the English literature revealed 23 cases of intussusception caused by abdominal trauma, with only 8 cases in preadolescents. ${ }^{2,3}$ Because the typical presentation of sudden onset of intermittent and severe cramping, vomiting, rectal bleeding, and a sausage-shaped abdominal mass are unusual in traumatic intussusceptions, we need to pay greater attention to avoid a delayed diagnosis. If the intussusception is not treated promptly, the vascular perfusion of the bowel may be compromised, resulting in bowel ischemia and possibly perforation. In the present report, we introduce the case of a 4-year-old girl who presented with intussusception after abdominal blunt trauma; in addition, we present a review of the literature.

\section{CASE REPORT}

A 4-year-old girl without underlying disease was admitted to the emergency department one day after blunt right upper abdominal trauma caused by a bicycle accident. The abdominal pain was

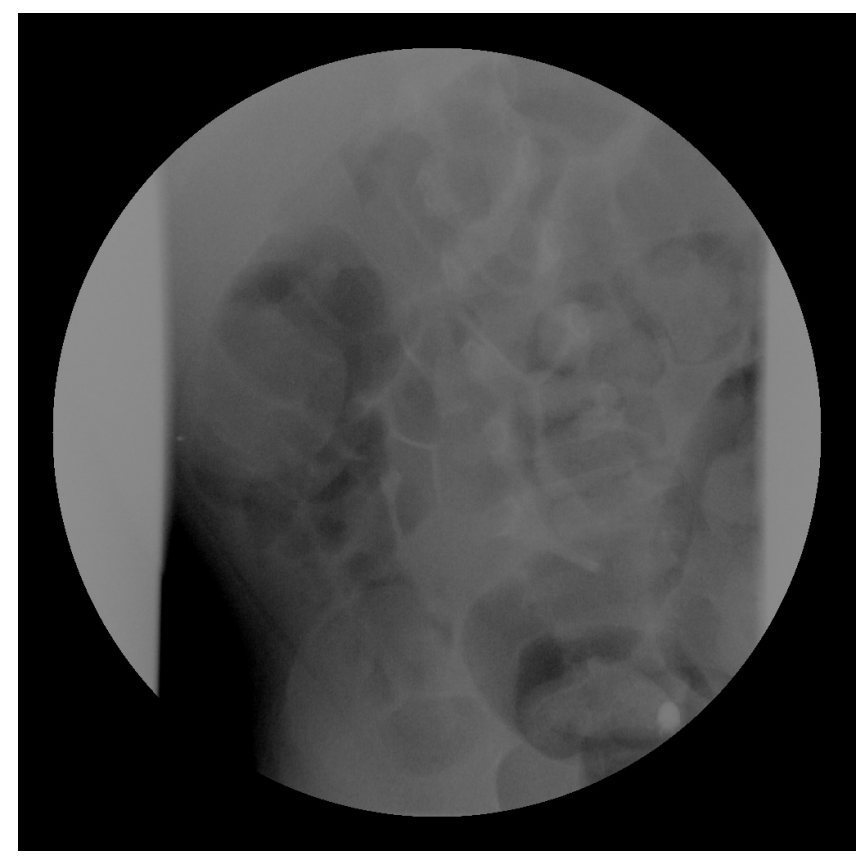

Fig. 1. Pre-reduction abdominal radiography reveals a mass-like lesion in the right upper quadrant. initially mild and tolerable, but progressively worsened. She complained of right upper abdominal pain but had no vomiting or diarrhea. On initial examination, there was mild abdominal distension and right upper quadrant tenderness with a scratch wound. Except for these findings, the physical examination was normal without fluid collection on focused assessment with ultrasonography for trauma (FAST). The patient's white blood cell count was mildly elevated at $8,900 / \mu \mathrm{L}$, hemoglobin level was $12.9 \mathrm{~g} / \mathrm{dL}$, platelet count was $211,000 / \mu \mathrm{L}$, erythrocyte sedimentation rate was $11 \mathrm{~mm} / \mathrm{hr}$, and C-reactive protein level was $3.44 \mathrm{mg} / \mathrm{dL}$. On abdominal radiography, a mass-like lesion was observed in the right upper quadrant (Fig. 1). We could not suspect that the abnormal finding was associated with trauma. For this reason, we consulted the general surgeons and pediatricians and requested radiology for abdominal ultrasonography. The radiologist confirmed ileocolic intussusception; fortunately, enteric perfusion was preserved, and other complications were not noted (Fig. 2). We decided to perform air reduction, after which the intussusception was successfully reduced. The patient was hospitalized in the pediatric ward for observation. Two days later, she was discharged to home without relapse or complication.

\section{DISCUSSION}

\section{Incidence and etiology}

Intussusception is a well-known medical condition, but traumatic intussusception is extremely rare. The mechanism underlying traumatic intussusception is unknown but has been proposed to be either a pathological peristaltic wave, localized spasm of a bowel segment, intramural hematoma, or edema after the trauma. ${ }^{4}$ The

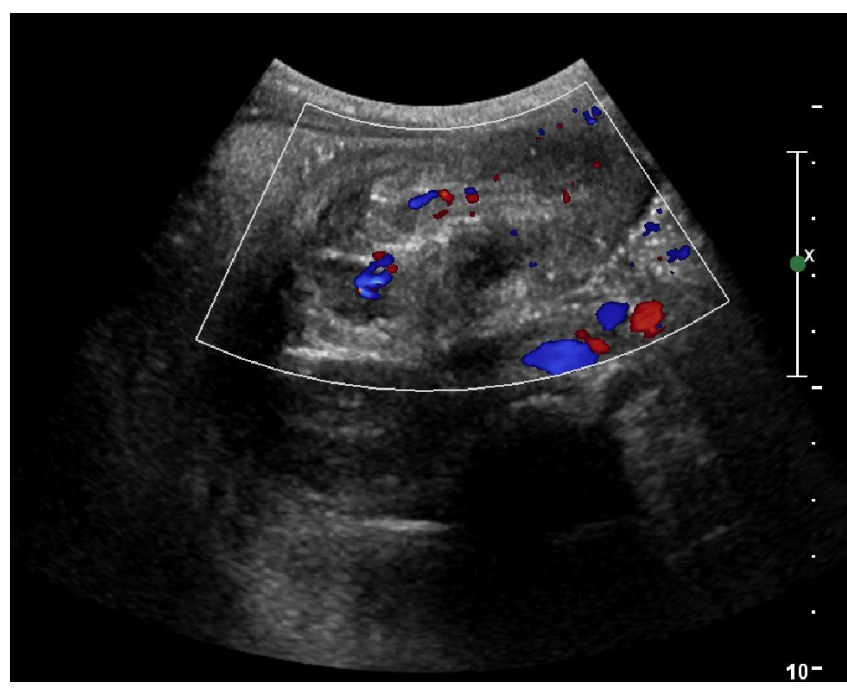

Fig. 2. Ultrasonographic color Doppler image reveals ileocolic intussusception with preserved enteric perfusion. 
Table 1. Characteristics of 9 children with blunt traumatic intussusception

\begin{tabular}{|c|c|c|c|c|c|c|c|c|c|c|}
\hline Reference & Sex & $\begin{array}{l}\text { Age } \\
(\mathrm{yr})\end{array}$ & $\begin{array}{l}\text { Abdominal } \\
\text { pain }\end{array}$ & Vomiting & $\begin{array}{l}\text { Abdominal } \\
\text { mass }\end{array}$ & $\begin{array}{l}\text { Bloody } \\
\text { stool }\end{array}$ & Location & Treatment & $\begin{array}{l}\text { Extraintestinal } \\
\text { organ damage }\end{array}$ & Outcome \\
\hline Kennedy ${ }^{5}$ & $M$ & 6 & Yes & Yes & Yes & No & Ileoileal & MR & None & Uncomplicated \\
\hline Mitchell $^{6}$ & $\mathrm{~F}$ & 10 & Yes & Yes & No & No & Jejunoileal & $\mathrm{MR}$ & None & Uncomplicated \\
\hline Badertscher $^{7}$ & $\mathrm{M}$ & 9 & Yes & No & No & No & Ileoileal & $\mathrm{MR}$ & None & Uncomplicated \\
\hline Isbister ${ }^{8}$ & $\mathrm{M}$ & 10 & Yes & No & No & No & Jejunoileal & $\mathrm{MR}$ & None & Uncomplicated \\
\hline LeBlanc $^{9}$ & $M$ & 8 & Yes & Yes & Yes & No & Jejunoileal & MR after HR & Pancreatitis & Uncomplicated \\
\hline Saxena et al. ${ }^{10}$ & $\mathrm{~F}$ & 4 & Yes & Yes & No & No & Ileoileal & BR after MR & None & Uncomplicated \\
\hline Erichsen et al. $^{2}$ & $\mathrm{M}$ & 6 & Yes & Yes & Yes & Yes & Ileoileal & BR after MR & None & Uncomplicated \\
\hline Lu et $a l^{3}$ & $\mathrm{M}$ & 12 & Yes & Yes & No & No & Jejunojejunal & Conservative & Pancreatitis & Uncomplicated \\
\hline Present study & $\mathrm{F}$ & 4 & Yes & No & No & No & Ileocolic & AR & None & Uncomplicated \\
\hline
\end{tabular}

$M R$, manual reduction; $H R$, hematoma removal; $B R$, bowel resection; $A R$, air reduction.

present case had no history of abdominal disease and no structural abnormalities such as bowel wall edema or hematoma; therefore, we suggested that the cause was pathological peristalsis or localized spasm.

\section{Clinical characteristics and diagnosis}

Classical intussusceptions commonly occur in the ileocolic region, with symptoms of intermittent cramping abdominal pain, a palpable abdominal mass, nausea, bloody stool, and fever. However traumatic intussusception presented with different clinical manifestations. The small bowel is commonly involved, and hematochezia and a palpable abdominal mass are present in less than half the cases. ${ }^{2}$ In previous studies, intussusceptions occurred most often near the ileoileal (4 cases), jejunoileal (3 cases), or jejunojejunal ( 1 case) bowel segments. Interestingly, the ileocolic segment was involved in the present case (Table 1). ${ }^{2,3,5-10}$

Most diagnoses of intussusception are confirmed using abdominal ultrasonography, with sensitivity, specificity, positive predictive value, and negative predictive value of $97.9 \%, 97.8 \%, 86.6 \%$, and $99.7 \%$, respectively. However, emergency physicians generally perform FAST, which does not examine the bowel, in trauma patients instead of routine ultrasonography. Therefore, intussusception may be misdiagnosed, unless we pay attention to abdominal pain.

\section{Treatment and outcome}

Traumatic intussusceptions are usually treated with surgery (manual reduction, bowel resection, and hematoma removal). ${ }^{2}$ Only 1 patient was managed conservatively with nasogastric tube decompression, bowel rest, total parenteral nutrition, and close monitoring in the pediatric intensive care unit. ${ }^{3}$ In our case, successful radiological reduction was performed using pneumatic reduction. To the best of our knowledge, this is the first report of air reduction performed for traumatic intussusception. We suggest that air reduction can be performed depending on the location of the lesion. This case is unique, considering an intussusception involving the ileocolic segment where air reduction is appropriate. Furthermore, ultrasonography revealed no other complications associated with blunt trauma. In all of the traumatic intussusceptions found in our literature review, the outcomes were favorable with no reports of complications.

\section{CONFLICT OF INTEREST}

No potential conflict of interest relevant to this article was reported.

\section{REFERENCES}

1. Bines JE, Liem NT, Justice FA, et al. Risk factors for intussusception in infants in Vietnam and Australia: adenovirus implicated, but not rotavirus. J Pediatr 2006;149:452-60.

2. Erichsen $D$, Sellstrom $H$, Andersson $H$. Small bowel intussusception after blunt abdominal trauma in a 6-year-old boy: case report and review of 6 cases reported in the literature. J Pediatr Surg 2006;41:1930-2.

3. Lu SJ, Goh PS. Traumatic intussusception with intramural haematoma. Pediatr Radiol 2009;39:403-5.

4. Komadina R, Smrkolj V. Intussusception after blunt abdominal trauma. J Trauma 1998;45:615-6.

5. Kennedy $\mathrm{CH}$. Ileal intussusception following severe trauma. Lancet 1920;1:1008-9.

6. Mitchell DA. Traumatic intussusception. Br Med J 1925;18:734.

7. Badertscher VA. Traumatic triple intussusception of the ileum of a child. JAMA 1939;112:422-3.

8. Isbister WH. Enteric intussusception after acute trauma. Am J Surg 1970;120:101-2.

9. LeBlanc KE. Jejuno-jejunal intussusception in a hemophiliac: 
a case report. Ann Emerg Med 1982;11:149-51.

10. Saxena AK, Sodhi KS, Khandelwal S, Rao KL, Suri S. Blunt ab- dominal trauma: an unusual cause of intussusception. Pediatr Radiol 2004;34:364. 